\title{
Joint Earthquake-Snow Hazard Characterization and Fragility Analysis of Wood-frame Structures
}

\author{
Yue Wang \\ Postdoctoral Research Associate, Dept. of Civil and Environmental Engineering, University of \\ Vermont, Burlington, USA \\ David V. Rosowsky \\ Provost and Senior Vice President, Professor of Engineering, University of Vermont, Burlington, USA
}

\begin{abstract}
This paper presents a study to statistically characterize the joint earthquake-snow hazard and subsequently develop maximum inter-story drift fragility curves for a series of archetype woodframe structures. Of particular focus are structures built in heavy-snow regions where seismic design may govern (and hence the roof snow load contributes additional seismic mass). While load standards such as ASCE 7 provide guidance on combining design loads for life safety design, for example, when considering base shear, guidance is not yet available for other performance levels (or limit states with specified non-exceedance probabilities), other structural responses (e.g., maximum inter-story drift), and hazard levels other than that implied in the life safety design (e.g., 2\%/50 years). All of these are expected to become more significant as performance based-design procedures continue to evolve and gain acceptance in the design community. Using Stampede Pass, WA as the study site, snow loads and earthquake loads were modeled as stochastic pulse processes and the joint snow-earthquake hazard contours were constructed (using simulation) to characterize the joint snow-earthquake hazard at different hazard levels. The uses of the joint hazard contours in performance-based engineering framework applications also are discussed and the suitability of current constant companion load coincidence factors, developed for use in strength-based design, is examined. The peak inter-story drift distribution and the seismic fragility curves were then developed for a set of archetype wood-frame structures at different joint hazard levels. The results show that the current strength-based design procedures are not risk-consistent for these types of wood-frame structures, affirming that recently developed displacement-based design procedures may provide a more risk-consistent design methodology.
\end{abstract}

\section{INTRODUCTION}

Performance-base engineering (PBE) tools for design and assessment/evaluation have evolved considerably in recent years and are gaining acceptance in the structural engineering community. Unlike current strength-based procedures that consider only the design against structural collapse during extreme events, PBE defines several performance requirements (e.g., immediate occupancy, life safety, collapse prevention) and corresponding hazard levels. The hazard level typically is described as an exceedance probability $\mathrm{X} \%$ in $\mathrm{Y}$ years (e.g., $2 \% / 50$ year). For example, in ASCE/SEI 41 (2006), the life safety performance requirement states that the probability of exceeding $2 \%$ drift under a 10\%/50 year seismic hazard event should not exceed 50\%. Although many advances have been made in the development of PBE considering a single hazard (e.g., earthquake or wind), very little has been reported considering multiple hazards (including concomitant hazards). The joint earthquake-snow hazard may be significant, for example, when considering the additional 
seismic mass resulting from roof snow load, especially in heavy-snow regions.

Many studies have examined the individual (marginal) and joint earthquakesnow hazard and the appropriate snow load companion factor (O'Rourke and Speck, 1992; Ellingwood and Rosowsky, 1996; Lee and Rosowsky, 2006; Yin et al., 2008). The studies by O'Rourke and Speck (1992), Ellingwood and Rosowsky (1996) and Yin et al. (2008) only consider the strength-based limit state. They did not consider maximum inter-story drift as the design response quantity of interest, but rather computed a strength-based reliability index $\beta$ considering life safety limit state. Therefore, the companion factor in the current ASCE 7 code, which is based on these studies, only applies to the case of strength-based design and life safety performance level. Lee and Rosowsky (2006) only considered the joint earthquake-snow hazard for sparse snow regions.

In this paper, the marginal earthquake and snow hazards were first properly modeled for the heavy-snow region (Stampede Pass, WA) and the joint histogram was constructed. Then the joint hazard contours corresponding to specific joint-hazard levels were developed. Finally, sets of joint-hazard design value pairs (at specific hazard levels) were selected and seismic fragility curves under different snow hazard levels were developed for wood-frame structures in the study region. The utility of this approach to performance-based design (PBD) application is also explored herein.

Three wood-frame building archetypes, selected from those used in the ATC-63 project (FEMA 2009) were considered in this study: a one-story commercial structure, a three-story commercial structure and a five-story residential structure. The details about archetype buildings can be found elsewhere (FEMA, 2009). All buildings are assumed to be located in Pacific Northwest (i.e., moderate seismic hazard region) on soil class D. Each rectangular-plan structure was designed using current force-base design (FBD) procedures. The design spectral acceleration is $0.74 \mathrm{~g}$ and the corresponding short-period spectral acceleration for the Maximum Considered Earthquake (MCE) $S_{M S}$ is $1.10 \mathrm{~g}$. In all these cases, the roofs are assumed to be heated and have slopes less than $30^{\circ}$. Also, all three structures are assumed to be located in exposure category C. Ground-to-roof snow load conversion factors are determined using the following equation in ASCE 7-10:

$$
p_{s}=0.7 C_{s} C_{e} C_{t} I p_{g}
$$

where $p_{s}$ is the sloped roof snow load, $p_{g}$ is the ground snow load, $C_{s}$ is the roof slope factor $\left(C_{s}=1.0\right), C_{e}$ is the exposure factor $\left(C_{e}=1.0\right), C_{t}$ is the thermal factor $\left(C_{t}=1.0\right)$ and $I$ is the importance factor $(I=1.0)$.

\section{HAZARD MODELING AND JOINT HAZARD CHARACTERIZATION}

\subsection{Snow hazard modeling}

The approach used by Wang and Rosowsky (2013) for modeling snow processes for heavysnow regions is adopted herein. A sample ground water equivalent snow depth record for one snow season in Stampede Pass, WA, along with a fitted trapezoid model, is shown in Figure 1. Four parameters are needed to fully describe the snow season model (trapezoid) shown in Figure 1: the duration of snow accumulation period $a_{1}$ (days), the peak intensity at the plateau $a_{2}(\mathrm{~m})$, the duration of the peak plateau period $a_{3}$ (days) and the meltoff slope at the end of the season $a_{4}$. These four parameters may exhibit pair-wise correlation, and this is considered herein. Parameters $a_{2}$ and $a_{3}$ are of greatest interest when characterizing the annual maximum water equivalent snow depth. Statistical information describing these four parameters was determined through an analysis of the 32 years of NCDC data (NCDC, 2014) discretized using the simple trapezoid model above. Table 1 presents a summary of the best-fit distribution parameters and pair- 
wise correlations for the four trapezoid model parameters.

Table 1: Statistics of trapezoidal parameters $\left(a_{1}-\right.$ $a_{4}$ ) for Stampede Pass, WA.

\begin{tabular}{|c|c|c|c|}
\hline$a_{1}-a_{4}$ & Distribution & Parameters & $\begin{array}{c}\text { Correlation } \\
\text { Coefficient }\end{array}$ \\
\hline$a_{1}$ & Lognormal & $\begin{array}{c}\lambda=4.8, \\
\xi=0.20\end{array}$ & $\begin{array}{c}\rho_{12}=0.087 \\
\rho_{13}=-0.72\end{array}$ \\
\hline$a_{2}$ & Lognormal & $\begin{array}{c}\lambda=3.7, \\
\xi=0.38\end{array}$ & $\begin{array}{c}\rho_{23}=0.28 ; \\
\rho_{24}=0.86\end{array}$ \\
\hline$a_{3}$ & ET-I & $\begin{array}{c}\mu=43.0, \\
\alpha=0.052\end{array}$ & $\rho_{34}=0.35$ \\
\hline$a_{4}$ & ET-I & $\begin{array}{c}\mu=2.9, \\
\alpha=0.57\end{array}$ & $\rho_{14}=0.25$ \\
\hline
\end{tabular}

Using the trapezoid pulse model described above and the parameters shown in Table 1, a total of 10,000 years of winter season snow events for Stampede Pass were simulated.

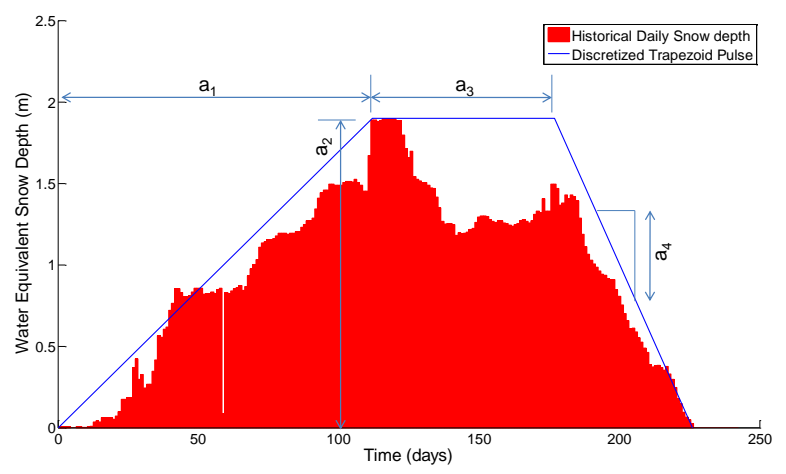

Figure 1: Trapezoid discretization of ground water equivalent snow depth record for one winter season, Stampede Pass, WA. (Note: 1 m=39.4 inches)

\subsection{Earthquake hazard modeling}

The earthquake event can be characterized as Poisson pulse process. The mean occurrence rate of earthquake events for a given site is assumed to be 0.05 to 0.10 per year and the duration of one earthquake event is assumed to be 30s (Ellingwood and Rosowsky, 1996). The intensity of the seismic hazard can be measured by the maximum peak ground acceleration (PGA) or maximum spectral acceleration $\left(S_{a}\right)$ in a given reference period $T$ (e.g., 50 years). In this study, the intensity measurement index was selected as $S_{a}$ to be consistent with the codified seismic design value (spectral acceleration) in the ASCE 7-10 design map. This intensity of maximum $S_{a}$ in $T$ years is assumed to follow an Extreme Type-II (ET-II) distribution (Cornell, 1968) with the cumulative distribution function $(\mathrm{CDF})$ is given by:

$$
F_{\text {max }}(x)=\exp \left[-(u / x)^{k}\right]
$$

where the $x$ is the maximum spectral acceleration $S_{a}$ in $T$ years, and the $u$ and $k$ are site-specific ET-II scale and shape parameters which are calculated using the data from the United States Geological Survey (USGS, 2014). In this study, the reference period $T$ is taken as 50 years to be consistent with the data provided by USGS which are based on a 50 years reference period. For Stampede Pass, WA, these parameters were calculated as $u=0.1855$ and $k=2.480$. Based on the Poisson pulse process, the CDF of the intensity of $S_{a}$ for each individual load pulse (earthquake event) can then be obtained by:

$$
F(x)=1+\ln \left[F_{\max }(x)\right] / \lambda T
$$

where the $\lambda$ is the mean occurrence rate and $T$ is the reference period (50 years).

Using the Poisson pulse process described above, a total of 10,000 years of earthquake event were simulated. Figure 2 shows a simulated 10,000 years record of earthquake occurrence for Stampede Pass, WA.

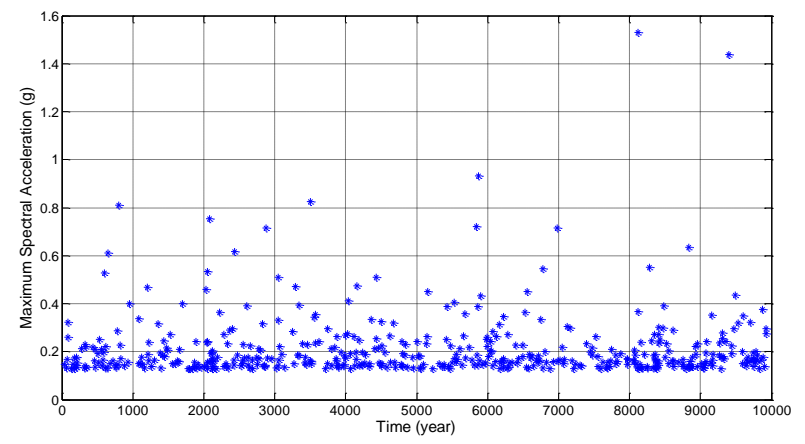

Figure 2: Simulated earthquake events history for Stampede Pass, WA.

\subsection{Bivariate hazard contour}

Once both the snow and earthquake time histories (pulse processes) are simulated, it is a simple matter to combine them and characterize 
the joint snow-earthquake hazard. For Stampede Pass, WA, a total of 317 joint earthquake (EQ) spectral acceleration and snow depth (SD) data pairs were generated over a 10,000 year period. The joint histogram can be constructed and the joint exceedance probability of EQ and SD can then be determined. Once the joint exceedance probability (joint complementary cumulative) distribution for EQ and SD is established, contours corresponding to different hazard levels (i.e., having different annual exceedance probabilities) can be generated, considering the mean annual occurrence rate $k=317 / 10000=$ 0.00317 per year. Events described by EQ and SD data pairs that fall along the same contour would therefore have the same joint annual exceedance probability. Contours corresponding to $2 \% / 50$ year, $10 \% / 50$ year and $50 \% / 50$ year hazard levels are shown in Figure 3 , along with 10,000 years of simulated EQ and SD data pairs. These three contours correspond to joint annual exceedance probabilities of $0.04 \%, 0.2 \%$ and $1.4 \%$, and mean recurrence intervals (MRI's) of 2475 years, 475 years and 71 years, respectively.

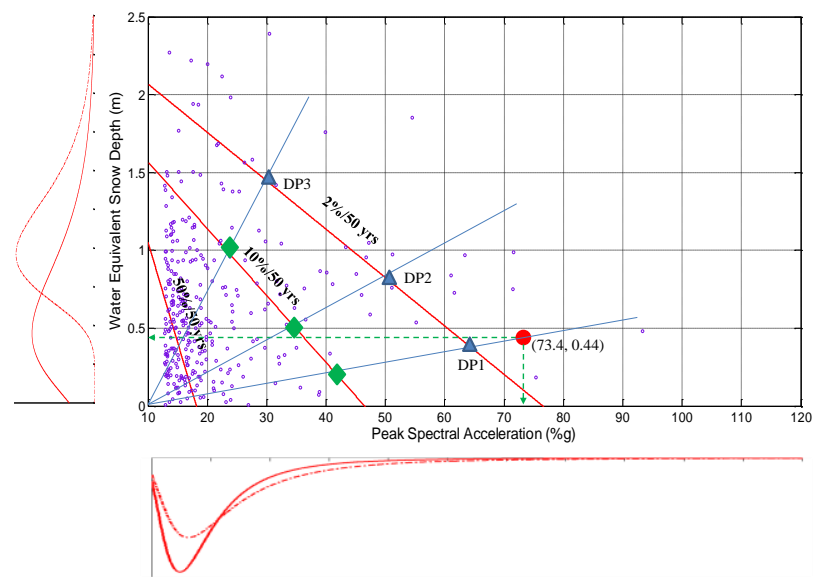

Figure 3: Hazard level contours showing simulated earthquake and annual maximum snow event, marginal distributions and factored design values for Stampede Pass, WA. (Note: 1 m=39.4 inches)

Also shown on Figure 3 are the marginal distributions for earthquake spectral acceleration and snow depth during each joint earthquake-snow event. Two marginal distributions are shown below the horizontal axis: (1) a solid line representing the marginal distribution of peak spectral acceleration conditioned on the occurrence of a joint snow event, taken as the peak $S_{a}$ of the simulated earthquake event that occur simultaneously with a snow event. Note that this marginal distribution is individual event intensity distributions, not annual maximum or 50-year maximum distributions. This marginal distribution was determined directly from the simulation results used to construct Figures 3. Thus, the marginal distribution of peak spectral acceleration is the distribution of peak spectral acceleration conditioned on the occurrence of a joint snow event; (2) a dash line representing the Extreme Type-II (ET-II) distribution for the 50-year maximum (extreme value) peak spectral acceleration (i.e., non-conditional, independent of any assumption of coincidence with a non-zero snow event), developed using the parameters from USGS (See Eq.(2) ). Note that this 50-year maximum distribution forms the basis for the $S_{a}$ design values (e.g., 475-year MRI (10\%/50 year)) used in current ASCE 7 codes (ASCE, 2010). Since the winter snow season length is shorter than a year, the 475year MRI value of (marginal) $S_{a}$ taken from the solid line (earthquake conditioned on snow season only) is smaller than the 475-year MRI (10\%/50 year) value in ASCE 7 which is taken from the dash line (non-conditional earthquake). Also shown next to the vertical axis are two marginal distributions: (1) a solid line representing the marginal distribution of snow depth conditioned on the occurrence of a joint earthquake event, taken as the snow depth presents when an earthquake event occurs, and (2) a dash line representing the distribution of annual maximum snow depth, developed from the simulated annual maximum snow depth data (i.e. non-conditional).

As seen in Figure 3 for this particular case, the current snow companion factor of 0.2 corresponds to the modal value of the marginal 
distribution of snow depth conditioned on the occurrence of an earthquake event (the solid line marginal distribution next to the vertical axis), which represents the maximum likelihood snow load (depth) given the occurrence of an earthquake with intensity of $S_{a}$. For Stampede Pass, WA, the modal value of simulated snow depth, conditioned on the occurrence of an earthquake event, is $0.44 \mathrm{~m}$ and the factored design snow depth is $0.2 * 2.2=0.44 \mathrm{~m}$, where $2.2 \mathrm{~m}$ is the snow depth converted from the nominal design snow load. Therefore, the current load combination with a snow companion factor of 0.2 represents the most likely snow occurrence scenario conditioned on the occurrence of an earthquake event at Stampede Pass, WA.

However, this site-specific modal value of simulated snow depth, conditioned on the occurrence of an earthquake event, does not always coincide with the factored design snow depth. Thus, from the standpoint of the hazards themselves, this constant snow companion factor may not provide a consistent means of selecting joint hazard design values, as would be of significance in a PBD procedure. However, current strength-based design procedures are developed to ensure, in a broad sense, that target reliability levels are met. Ellingwood and Rosowsky (1996) and Yin et. al., (2008) showed that the 0.2 snow companion factor was appropriate for life safety (considering base shear) for most cases except for heavy-snow regions. Therefore, in the current strength-based design philosophies (such as LRFD), load combination factors were determined through reliability analyses in which the hazard and structural response (e.g., base shear) were convolved to evaluate a limit state probability. In the PBD philosophies, the hazard and structural response should be separated, implying the non-convolved hazard characterization and structural fragility analysis. Therefore, for the evolving PBD procedures (such as displacement-based design), a single constant snow companion factor, developed under strength-based design philosophies, likely is not appropriate.

\section{JOINT HAZARD CONTOURS AND SEISMIC FRAGILITY CURVES CONDITIONED ON SNOW}

Once the joint earthquake-snow hazard contours have been generated, pairs of the jointhazard design values (at specific hazard levels) can be identified for use in performance-based design applications. Figure 3 shows one possible approach (based on equally spaced radial vectors) for selecting three sets of "design value pairs" of earthquake (EQ) and snow depth (SD) for Stampede Pass, WA (shown as solid triangles for the 2\%/50 year hazard level and diamonds for the $10 \% / 50$ year hazard level). For example, if designing for the $2 \%$ in 50 year joint hazard level, one would check to ensure the design objective is met (i.e., performance limit is not exceeded) under each of the three design value pairs (illustrated by solid triangles as design point 1 (DP1), design point 2 (DP2) and design point 3 (DP3)), representing the high-EQ/low-SD $(0.65 \mathrm{~g}, 0.40$ $\mathrm{m})$, moderate-EQ/moderate-SD $(0.50 \mathrm{~g}, 0.80 \mathrm{~m})$ and low-EQ/high-snow $(0.30 \mathrm{~g}, 1.50 \mathrm{~m})$ cases.

We can now use the information shown in Figure 3 to make observations and comment on the relationship between design loads such as those specified in ASCE 7 and those associated with specific hazard levels (or MRI's) as might be used in PBD applications. In PBD, a range of different risk-based performance objectives are generally expressed in terms of a hazard level and a target performance level. As stated in ASCE/SEI 41 (2006), the life safety performance requirement corresponds to a $10 \% / 50$ year hazard level and a 50\% nonexceedance probability of the $2 \%$ drift limit. The factored design (ASCE 7) value pair for earthquake $S_{a}$ and snow depth is $(0.73 \mathrm{~g}$, $0.44 \mathrm{~m}$ ), which falls outside the $2 \% / 50$ year joint hazard contour, close to the $1 \% 50$ year joint hazard level. This suggests that the factored design values used in the codified combination, intended to correspond to the life 
safety performance objective, may be conservative in this particular case. Note that this is mainly due to the small number of concurrent earthquake-snow events (317 joint events in 10,000 years for this heavysnow/moderate earthquake region).

Once the joint earthquake-snow hazard design values (at specific hazard levels) are selected, the structure could be designed using the current FBD or recently proposed DDD procedures (Pang and Rosowsky, 2009). Then, the structural response (i.e., inter-story drift in this case) can be analyzed and the fragility surface for joint earthquake-snow hazard can be developed. As an example, we consider three baseline structures designed by FBD procedure using the factored ASCE 7 design value pair.

For the case of two joint hazards (earthquake and snow), the fragility function (surface) describes the probability that the peak response (e.g., inter-story drift) exceeds the prescribed (e.g., drift) limit associated with the specific performance requirement, at a given values of $S_{a}$ and snow depth. Lee and Rosowsky (2006) first presented such functions, considering joint earthquake and snow hazards, as three-dimensional surfaces. Alternatively, a set of seismic fragility curves at specified (deterministic) snow loads can be developed. These are, in essence, contour projections of the joint fragility surface at the given snow load levels. In this study, the latter method is adopted. Fragility functions typically are fit using a lognormal distribution (Li et al. 2010; Wang and Rosowsky, 2014).

In order to generate the seismic fragility curves under different snow loads, a series of NLTHA's were performed to obtain the peak inter-story drift distribution. A total of 22 biaxial ground motion sets selected from PEER_NGA database (PEER, 2013) served as input to the NLTHA's. The results can then be used to assess the probability that the peak inter-story drift in the structure exceeds the drift limit conditioned on each level of seismic load and snow load. The procedures of constructing fragility curves using peak inter-story drift distributions from NLTHA results is described elsewhere (Lee and Rosowsky, 2006; Wang and Rosowsky, 2014). Figure 4 shows a suite of seismic fragility curves considering different snow loads, ranging from 0 - 450 psf (Note: 1 psf $=47.88 \mathrm{~N} / \mathrm{m}^{2}$ ) for a one-story archetype structure.

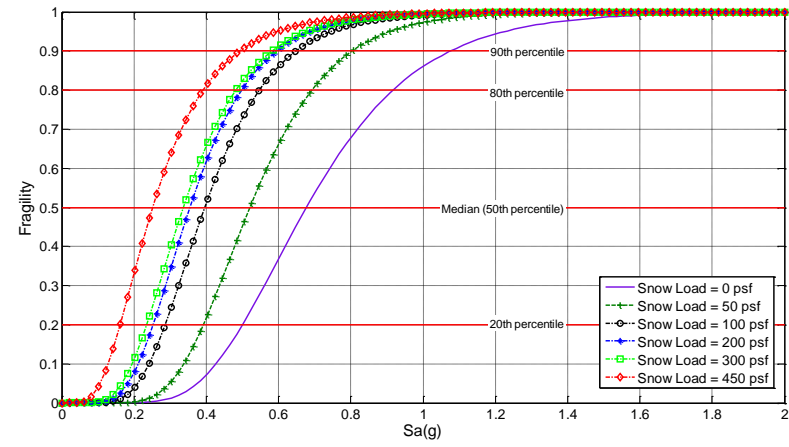

Figure 4: Fragility curves of archetype 3 (onestory) under different snow load levels (Note: 1 psf $=47.6 \mathrm{~N} / \mathrm{mm}^{2}$ )

Another way to view the results is to look at risk contours, for example considering the risk of a particular structure at different joint earthquake-snow hazard levels. Such risk contours are simply equal-probability projections of the fragility surface on the plane of earthquake and snow. In order to generate the risk contours, the corresponding values of earthquake and snow load at specified failure probabilities were extracted from the seismic fragility curves as in Figure 4. Then for each level of failure probability, a line was fit using the five extracted value pairs of joint earthquake and snow combinations. Figure $5(\mathrm{a}, \mathrm{b}, \mathrm{c})$ presents these four risk contours corresponding to failure probabilities of 20,50, 80 and 90 percent for three archetype structures. For practical use, risk contours other than these four can be linearly interpolated. Also shown in Figure $5(a, b, c)$ is the codified FBD design point $(0.73 \mathrm{~g}, 0.44 \mathrm{~m})$ used to design these archetype structures, which corresponds to the $10 \% / 50$ year earthquake-only hazard level and 0.2 snow companion factor. 


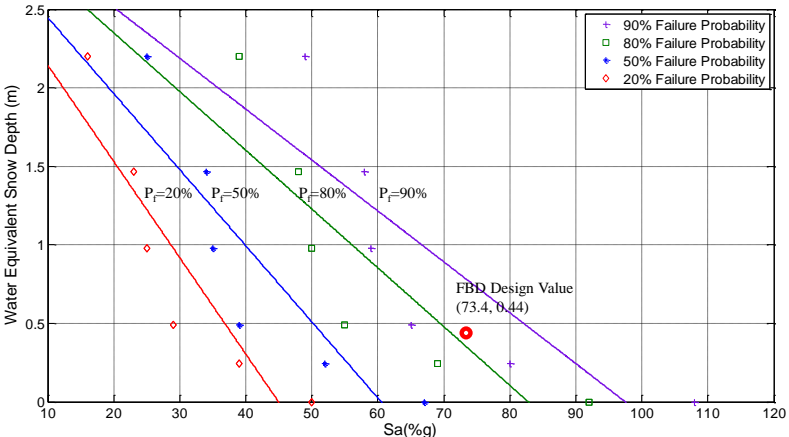

(a)

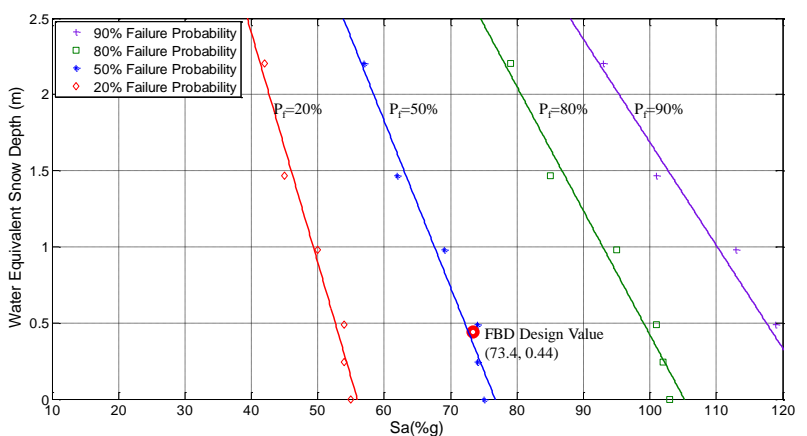

(b)

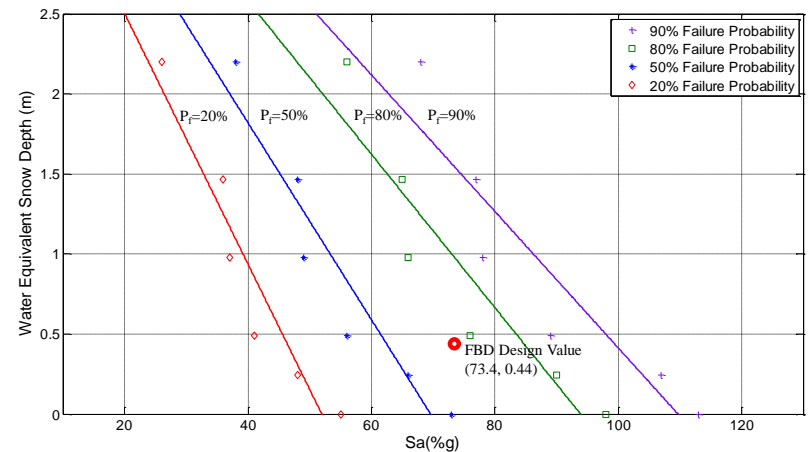

(c)

Figure 4: Risk (failure probability) contours of (a) archetype 3 (one-story) (b) archetype 9 (three-story) archetype 16 (five-story) under combined earthquake and snow hazard (Note: 1 psf $=47.6$ $\mathrm{N} / \mathrm{mm}^{2}$ )

According to the life safety target performance requirement specified by ASCE/SEI 41 (2006), the probability of peak inter-story drift exceeding the $2 \%$ drift limit should not exceed $50 \%$ (median). In figure $5 \mathrm{~b}$, the FBD design point lies close to the $50 \%$ failure probability contour, which suggests that the FBD three-story structure barely meets the life safety target performance requirement. However, as seen in Figure 5a, the FBD design point lies between the $80 \%$ and $90 \%$ risk contours, and in Figure 5c, the FBD design point lies between the $50 \%$ and $80 \%$ risk contours, suggesting that both the FBD onestory and five-story structures fail the life safety target performance requirement and therefore the design is non-conservative. This illustrates a lack of risk-consistency in current design procedures when considering different heights of wood-frame structures (from low-rise to moderate/high-rise buildings). If future codes move towards a uniform-risk design philosophy (Li et. al., 2010), this issue of lack of riskconsistency will need to be addressed. The seismic DDD procedure proposed by Pang and Rosowsky (2009) suggests one risk-consistent (uniform-risk) design approach for wood-frame structures in seismic regions. It might also provide a means for considering load combination factors selected to achieve, in a broad sense, a uniform-risk design considering joint hazards.

\section{SUMMARY AND CONCLUSIONS}

This paper presents results from a series of studies to statistically characterize the joint earthquake-snow hazard and generate peak inter-story drift fragility curves for a set of archetype wood-frame structures. Using Stampede Pass, WA, a heavy snow region, as the study site, the snow season was represented using a simple trapezoidal pulse model. The earthquake event was characterized using a Poisson pulse process. The joint earthquakesnow hazard contours are then constructed to characterize the joint hazard corresponding to different hazard levels.

To further investigate the application of the joint snow-earthquake hazard contours in PBD framework, three design value pairs and the factored ASCE 7 design value were selected. The results confirm that the current single constant snow companion factor, developed 
considering strength-based design, may not be appropriate for the use with evolving PBD procedures. Then, structural response (i.e., inter-story drift in this case) was analyzed and fragility curves for joint earthquake-snow hazard were developed. Next, using three baseline structures designed by FBD procedures and the factored ASCE 7 design value pair, joint earthquake-snow fragility curves were developed. The results also were presented in the form of risk contours. A lack of risk-consistency in current design procedures was illustrated for wood-frame structures of different heights. Recently proposed DDD procedures were then suggested as one means for considering multiple hazards as we move towards a uniform-risk design philosophy.

\section{REFERENCES}

American Society of Civil Engineers (ASCE) (2010). Minimum Design Loads for Buildings and Other Structures (ASCE/SEI 7-10), American Society of Civil Engineers, Reston, VA.

American Society of Civil Engineers (ASCE) (2006). Seismic Rehabilitation of Existing Buildings (ASCE/SEI 41-06), American Society of Civil Engineers, Reston, VA.

Cornell, C. A. (1968). "Engineering seismic risk analysis," Bulletin of the Seismological Society of America, 58(5), 1583-1606.

Ellingwood. B. R., and Rosowsky, D.V. (1996), "Combining snow and earthquake loads for limit state design," ASCE Journal of Structural Engineering, 122(11), 1364-1368.

Federal Emergency Management Agency (2009). "Quantification of building seismic performance factors," Applied Technology Council ATC-63 Project Report, FEMA P695, Washington, DC.

Lee, K. H. and Rosowsky, D.V. (2006), "Fragility analysis of woodframe buildings considering combined snow and earthquake loading," Structural Safety, 28, 289-303.

Li, Y., Yin, Y., Ellingwood, B. R. and Bulleit, W. M. (2010). "Uniform hazard versus uniform risk bases for performance-based earthquake engineering of light-frame wood construction," Earthquake Engineering and Structural Dynamics, 39, 1199-1217.

National Climatic Data Center (NCDC) (2014). <http://www7.ncdc.noaa.gov/CDO/dataprodu ct> (Mar. 28, 2014).

O'Rourke, M. and Speck, R. (1992), "Roof snow loads for seismic design calculations," ASCE Journal of Structural Engineering, 118(9), 2338-2350.

Pacific Earthquake Engineering Research Center (PEER) (2013). "PEER Ground Motion Database."

http://peer.berkeley.edu/peer_ground_motion _database> (Feb. 12, 2013).

Pang, W.C. and Rosowsky, D.V. (2009). "Direct Displacement Procedure for Performancebased Seismic Design of Mid-rise Woodframe Structures," EERI Earthquake Spectra, 25(3), 583-605.

Wang, Y., Rosowsky, D.V. and Pang, W. (2010), "Performance-Based Procedure for Direct Displacement Design of Engineered Woodframe Structures," ASCE Journal of Structural Engineering, 136(8), 978-988.

Wang, Y. and Rosowsky, D.V. (2013), "Characterization of joint wind-snow hazard for performance-based Design," Structural Safety, 43, 21-27.

Wang, Y. and Rosowsky, D.V. (2014), "Effects of earthquake ground motion selection and scaling method on performance-based engineering of wood-frame structures," ASCE Journal of Structural Engineering, to appear.

Yin, Y.J., Li, Y. and Bulleit, W.M. (2008), "Snow and earthquake load combination considering snow accumulation," Proc. of the $14^{\text {th }}$ World Conference on Earthquake Engineering, International Association for Earthquake Engineering (IAEE), Tokyo, Japan.

Yin, Y.J., Li, Y. and Bulleit, W.M. (2011), "Stochastic modeling of snow loads using a filtered poisson process," Journal of Cold Region Engineering, 25(1), 16 - 36. 